\title{
TITLE:
}

\section{THE COLOUR PATTERN OF SPADELLA ANGULATA TOKIOKA}

$\operatorname{AUTHOR}(\mathrm{S})$ :

Tokioka, Takasi; Bieri, Robert

\section{CITATION:}

Tokioka, Takasi ...[et al]. THE COLOUR PATTERN OF SPADELLA ANGULATA TOKIOKA. PUBLICATIONS OF THE SETO MARINE BIOLOGICAL LABORATORY 1966, 14(4): 323-326

ISSUE DATE:

1966-09-20

URL:

http://hdl.handle.net/2433/175444

RIGHT: 


\title{
THE COLOUR PATTERN OF SPADELLA ANGULATA TOKIOKA ${ }^{1)}$
}

\author{
TAKASI TOKIOKA \\ Seto Marine Biological Laboratory \\ and \\ ROBERT BIERI \\ Antioch College, Ohio, U.S.A. \\ With 1 Text-figure
}

The new dredge for collecting meiobenthonic animals, Dragonet II, which is now in the final experimental stage was tested at a $50 \mathrm{~m}$ deep station off Seto-Zaki about $3.2 \mathrm{~km}$ south of the Seto Marine Biological Laboratory on the morning of June 13, 1966. In the material collected by a 10 minute dragging, six spadellas were found in the bottom net sample and one in the top net sample. These spadellas are all devoid of a prominent cement gland at the aperture of the seminal receptacle. The lateral fin is always extended anteriorly beyond the trunk-tail septum for a considerable length. For these two important characteristics, they were identified as $S$. angulata, although the shape of the fully matured seminal vesicle was left unknown.

That afternoon, while he was examining the specimens, BrERI noticed that a single $5.8 \mathrm{~mm}$ long individual retained still some colouration, and called the attention of Tokioka to it. Tokioka, then observed the specimen carefully under different illumination on different backgrounds and found that the tail segment of that individual was provided with a unique colour pattern on the dorsal side. Once more the specimen was examined very closely by both of the authors before the colour faded the next morning. The next afternoon, in the top net sample, a second specimen $4.4 \mathrm{~mm}$ long was found with the same colour pattern. The details of the colour pattern are given in the following section. BIERI (1966) briefly reviewed colour in other chaetognaths. This seems to be the first notice of a mottled colour pattern in chaetognaths. Possibly the colour pattern appearing as grey at $50 \mathrm{~m}$ depth is an aid to blending with the sand substrate.

A great number of Spadella cephaloptera, both live and preserved, have been studied by many biologists so far, but no one has ever reported such a strange colour pa-

1) Contributions from the Seto Marine Biological Laboratory, No. 459 and Studies of Meiobenthos by Dragonet, No. 1.

Publ. Seto Mar. Biol. Lab., XIV (4), 323-326, $1966 . \quad$ (Article 21) 
ttern on them. Possibly, the present colour pattern is not an exceptional one, but can be observed frequently on perfect live or freshly preserved specimens which share the morphological characteristics shown by the present specimen. If this is true, the special colour pattern of the present specimen might be the decisive characteristic to support the separation of $S$. angulata from $S$. cephaloptera.

The construction of Dragonet and its tests are being carried out by the partial financial support through grants from the Japan Society for the Promotion of Science and the National Science Foundation as part of the Japan-U.S. Cooperative Science Program. Our hearty thanks are presented to Messrs. S. URA and S. SAKAI of the Seto Marine Biological Laboratory for their help during the work.

\section{Colour pattern on the dorsal side}

Head: Two pairs of small faint orange-brown spots near the anterior end. A much larger spot of a similar colour at each antero-lateral corner of corona ciliata. Eye-pigment black.

Trunk: A small dark brownish spot at the base of each posterior prominent lateral sensory patch, approximately at the level of the posterior third. Five pairs of light orange-brown spots are arranged in a series, two posterior pairs are much larger than anterior ones.

Tail: Eight pairs of orange-brown spots in a series. Spots of the second to the sixth pairs are each along the lateral edge of the segment, the sixth pair at the anterior end of the seminal vesicle are the largest and only they are coloured dark brownish. Others are all much lighter. There are a series of five light orange-brown rings on the median line, nearly round to oval in shape and each containing a large sensory patch at the centre. These sensory patches each bear a row of sensory hairs arranged in the sagittal plane (Fig: A). In addition to the rings, two more small median spots of the same colour are found respectively near and at the posterior end of the tail segment.

\section{Colour pattern on the ventral side}

Head: A pair of large dark brown pigment spots on the neck region.

Trunk: Three pairs of dark brown spots, each spot along the lateral edge of the trunk. The first pair are smaller than others.

Tail: Five pairs of prominent dark brownish colour spots anterior to the seminal vesicle, each spot along the lateral edge of the segment. One pair of such spots, but smaller in size and lighter in colour, posterior to the vesicle. Four pairs of small light brownish colour spots are arranged in a series. A small median spot at the posterior end of the segment. It is light brownish orange. 

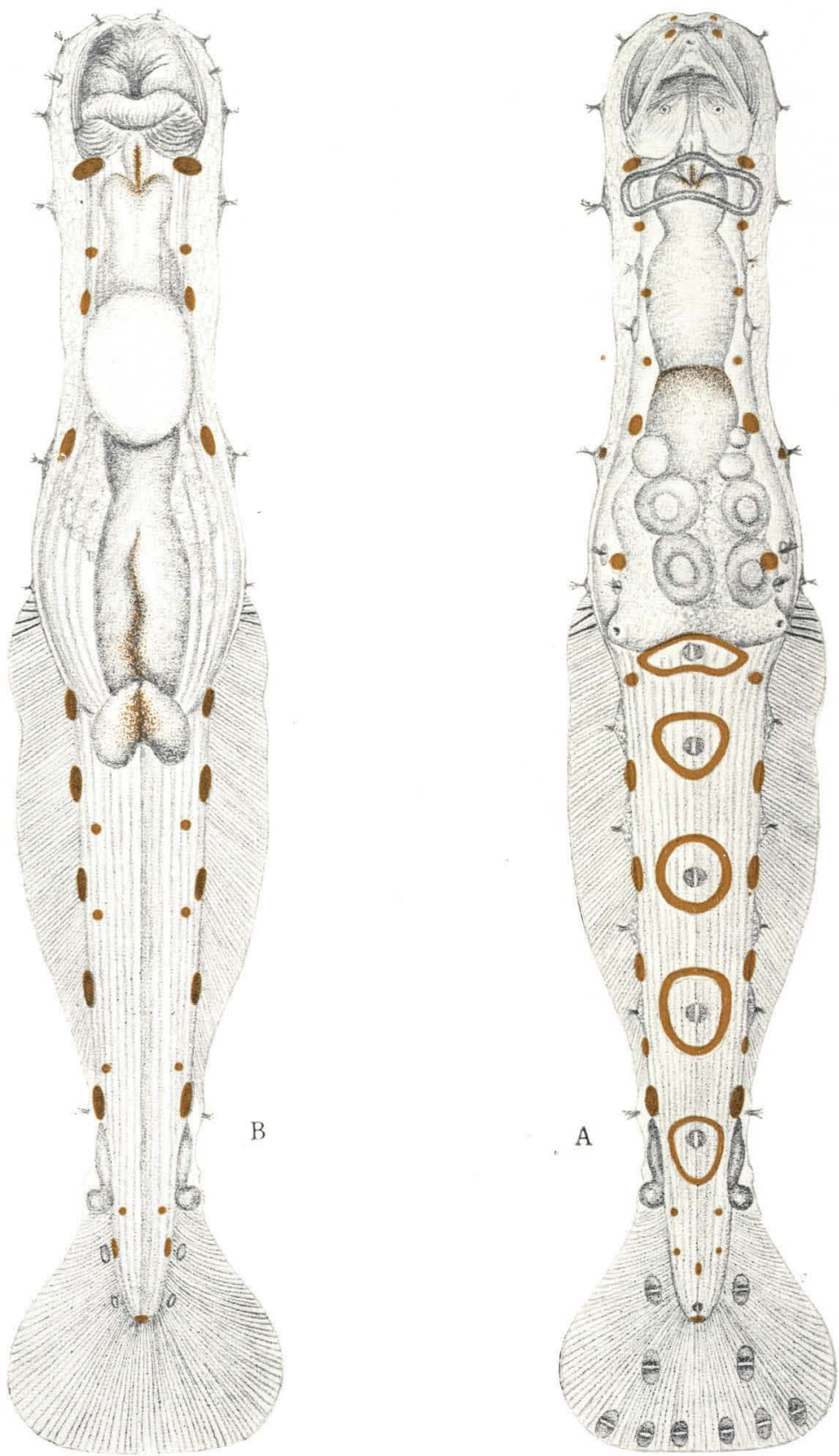

Fig. 1. Spadella angulata ТоктокА. A-Dorsal side of the $5.8 \mathrm{~mm}$ long individual, B-Ventral side of the same specimen. 


\section{Colouration of internal organs}

The axial portion of the pharynx and the small limited area of the intestine near the joint between it and the pharynx are coloured brownish. The posterior half of the intestine is cloured yellowish orange and this colouration becomes darker posteriorly. The posterior portion of the intestine everted out from the anus is coloured dark reddish along the middle fold which continues anteriorly along the intestinal lumen inside the body.

\section{REFERENCE}

BrERI, R. (1966): A pale blue chaetognath from Tanabe Bay. Publ. Seto Mar. Biol. Lab., Vol. 14, No. 1, pp. 21-22. 